\title{
Optimal sizing of distributed generation using firefly algorithm and loss sensitivity for voltage stability improvement
}

\author{
Zulkiffli Bin Abdul Hamid, Sylvester Jipinus, Ismail Musirin, Muhammad Murtadha Othman, \\ Rahmatul Hidayah Salimin \\ Faculty of Electrical Engineering, Universiti Teknologi MARA, Malaysia
}

\begin{tabular}{|c|c|}
\hline Article Info & ABSTRACT \\
\hline & \multirow{8}{*}{$\begin{array}{l}\text { This paper proposes an optimization technique for distributed generation } \\
\text { (DG) sizing in power system. The DG placement was done through Loss } \\
\text { Sensitive (LS) technique to determine the suitable locations. The LS index is } \\
\text { calculated such that the change in power losses is divided with generation } \\
\text { increment and a rank of buses is obtained to identify the suitable locations for } \\
\text { DG placement. Subsequently, a meta-heuristic algorithm, known as Firefly } \\
\text { Algorithm (FA) was run to obtain the optimal size or capacity of the DG. } \\
\text { The installation takes into consideration the aspect of voltage stability in } \\
\text { terms of total real power losses and voltage profiles to be improved in the } \\
\text { distribution system. Based on the experiment, the real power losses and } \\
\text { voltage profiles were improved significantly as a result of the DG placement. } \\
\text { In addition, the installation could prevent the power system from collapse as } \\
\text { the reactive loading was increased to maximum. }\end{array}$} \\
\hline Received May 1, 2019 & \\
\hline Revised Jul 3, 2019 & \\
\hline Accepted Jul 17, 2019 & \\
\hline Keywords: & \\
\hline Distributed generation & \\
\hline Firefly algorithm & \\
\hline Voltage stability & \\
\hline
\end{tabular}

Copyright $@ 2020$ Institute of Advanced Engineering and Science. All rights reserved.

Corresponding Author:

Zulkiffli Bin Abdul Hamid, Faculty of Electrical Engineering, Universiti Teknologi MARA, 40450 Shah Alam, Selangor, Malaysia.

Email: zulkiff19947@uitm.edu.my

\section{INTRODUCTION}

The recent approach by most utilities in fulfilling the ever-growing electricity demand is distributed generation (DG). There are many advantages as a result of DG installation in a distribution system. As has been reported in [1-4], the DG is able to improve power quality, voltage stability and reduce power losses due to various factors like poor switching operation, voltage dips, interruption, transient, and network disturbances at consumer side. It can also improve the efficiency of distribution systems if proper installation was carried out. As electric power generation, the DG system can provide real power to the distributed system network or the consumer side network [5]. With the purpose of providing a source of real power, the DG will not provide any reactive power to the system. However, the reactive power can be provided under certain circumstances, especially the one that relates to voltage stability. Due to the power loss which will result in insufficient power supply, mostly the location for installing the DG is at consumer side network. In addition, the inconsistence of power demand at consumer side is also one of the factors to install a DG. The optimal installation, sizing and operation of DG units connected directly to the network can be determined by several methods. Mainly, there are four methods can be used in optimal DG placement such as the L-index method, Voltage Stability Margin Index (VSMI) method, Voltage Performance Index (VPI) method and Loss Sensitivity Factor (LSF) [6-10]. Placement via LSF requires simulation of load flow to obtain the resulted real power loss with respect to the DG's injected real power (i.e. the DG capacity). Whichever location in the distribution system that has the lowest LSF value will be noted as the most suitable location for DG placement. The power rating for the DG which will be connected to the distribution system depends on the capacity of the system. This is divided according to the DG sizes as follows: $1 \mathrm{~kW}$ to $5 \mathrm{~kW}$ 
for micro, $5 \mathrm{~kW}$ to $5 \mathrm{MW}$ for small, $5 \mathrm{MW}$ to $50 \mathrm{MW}$ for medium and $50 \mathrm{MW}$ to $300 \mathrm{MW}$ for large DG size [11]. The technology used in distributed generation can be divided into several categories, such as renewable energy generation, modular generation and combined heat and power (CHP) generation [5]. The modular generation generates electricity from battery storage and it cannot provide large power demand. The combined heat and power (CHP) generation or simply co-generation is the one that generates electricity and useful heat from steam using the combination of fossil fuel, engine and gas turbine. Some of these types, however, have small disadvantages as they are not renewable and have small effect to the environment. In the renewable energy, it generates electricity from natural source such as geothermal, wind, hydro, biomass and solar. This type is greener to the world and the energy source is infinite.

There are many researches on optimal installation of distributed generation using various algorithms [12, 13]. Evolutionary Programming (EP), Particle Swarm Optimization (PSO), Genetic Algorithm (GA) and Differential Evolution (DE) are the examples. In comparison with traditional optimization techniques, meta-heuristic algorithms are more complex as they need many variables and parameters to be considered for a good accuracy. Firefly Algorithm (FA), developed by Yang in 2008 [14], is a meta-heuristic algorithm inspired from the adapted behavior of firefly swarms to develop optimizing function with multiple optima as an algorithm [15-18]. The FA is flexible in terms of implementation and problem formulation as compared to other algorithms. In [19], adaptive PSO was applied in the problem of DG and capacitor bank allocation. The adaptive version was produced by replacing the inertial weight equation in the original PSO's velocity update equation. Experiment on three different test systems verified the effectiveness of the adaptive PSO in solving the DG allocation problem. Later, article [20] proposed optimal DG allocation using Whale Optimization Algorithm (WOA). The research considers various types of DG resources like photovoltaic cells, fuel cells and kVAR compensators. Through comparison with other optimization methods, it was observed that the proposed method yields to the lowest power loss minimization and highest voltage profile improvement. A research that employed FA for optimal DG allocation was conducted in [21]. The research takes into consideration on voltage profile improvement besides power loss minimization in IEEE 33-bus radial network. However, the sizing focused on injected real power by DG instead of reactive power. Other researches on optimal DG allocation using various meta-heuristic algorithms can be found in [22-25].

In this study, the FA acts as an engine to find the optimal size of DG capacity. The aim of the optimization is to improve the voltage stability of distribution system, and this will be in terms of voltage profiles and real power losses. Prior to conducting the optimization, the identification of suitable locations for DG placement will be performed using the LS technique. This means that a rank of buses from the distribution system with their corresponding LS indices will be obtained as a result of load flow simulation. This paper is organized as follows: Section 2 will describe the proposed methodology and techniques to be implemented in this study, Section 3 analyzes the results with some interpretation related to voltage stability, and Section 4 concludes the overall findings of this study.

\section{RESEARCH METHOD}

The methodology of this study starts with the philosophy of Firefly Algorithm (FA), followed by the proposed problem formulation including the set of variables and constraints to be used in the FA and the overall algorithm or process specially designed for this study.

\subsection{Firefly algorithm}

The FA was inspired from fireflies behaviour of using the flash signal to attract the other potential fireflies [14, 18]. Based on Figure 1, the behaviour of the meta-heuristic FA is based on the following rule: all fireflies are considered unisexual and the attractiveness between them is directly proportional to their flashing light intensity or brightness.

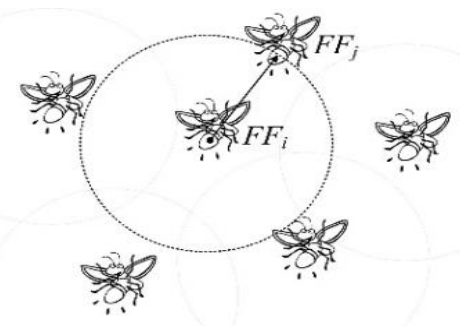

Figure 1. Firefly movement 
Thus, the movement of firefly will be from the one which is less bright to brighter firefly. However, as the distance between the two fireflies increases, the brightness of a firefly with respect to the other one decreases. If no brighter fireflies nearby, the less bright firefly will move randomly. The FA has two important parameters, which are light intensity and the formulation of attractiveness. The equation to represent the light intensity is given in (1)

$$
I(r)=I_{0} e^{-\gamma r^{2}}
$$

Where,

$I_{o}:$ light intensity of the source

$\Gamma$ : fixed light absorption

$R$ : singularity $(r=0)$

The formulation of attractiveness equation is given in (2)

$$
\beta=\beta_{0} e^{-r r^{2}}
$$

The distance between two fireflies is calculated using (3)

$$
r_{i j}=\left\|S_{i}-s_{j}\right\|=\sqrt{\sum_{k=1}^{k=n}\left(s_{i k}-s_{j k}\right)^{2}}
$$

Therefore, the final step in producing the new solution is done through (4)

$$
s_{i}=s_{i}+\beta_{0} e^{-r^{2}{ }^{2 i j}}\left(s_{j}-s_{i}\right)
$$

From (1) and (2) the FA is controlled by the attractiveness, $\beta$ and the fixed absorption coefficient, $\gamma$. If the $\gamma$ of the current position for $i$-th firefly is more than $j$-th firefly, then it will be $\beta=\beta_{0}$. Thus, it will move via attractiveness using (4). Otherwise, the firefly will move randomly. The general processes of FA are shown in Figure 2.

\subsection{Proposed Problem Formulation}

In this paper, the control variables in the FA optimization engine are the capacity of DG in the form of injected reactive power, $Q_{D G}$. The reactive power is limited between $Q_{D G \_ \text {min }}$ and $Q_{D G \_ \text {max }}$, i.e. the minimum and maximum capacity of the DG. The objective function is to minimize the real power loss in the system. The analysis will be conducted in IEEE 30-bus test system, hence there are thirty locations to be determined for DG placement. The overall optimization problem can be summarized as follows:

Minimize $\left\{f\left(Q_{D G 1}, Q_{D G 2}, \ldots Q_{D G i, \ldots} Q_{D G N}\right)=P_{\text {loss }}\right\}$

Subject to

$$
\begin{aligned}
& 0 \text { p.u. }<F V S I_{\max }<0.7 \text { p.u. } \\
& 0.85 \text { p.u. }<V_{\min }<1.05 \text { p.u. } \\
& Q_{D G_{-} \text {min }}<Q_{D G}<Q_{D G \_ \text {max }} \\
& \Sigma P_{G}=\Sigma P_{D}+P_{\text {loss }} \\
& \Sigma Q_{G}=\Sigma Q_{D}+Q_{\text {loss }}
\end{aligned}
$$

Control variables in the FA are

$$
S_{i}=\left[Q_{D G 1}, Q_{D G 2}, \ldots Q_{D G i} \ldots Q_{D G N}\right]
$$




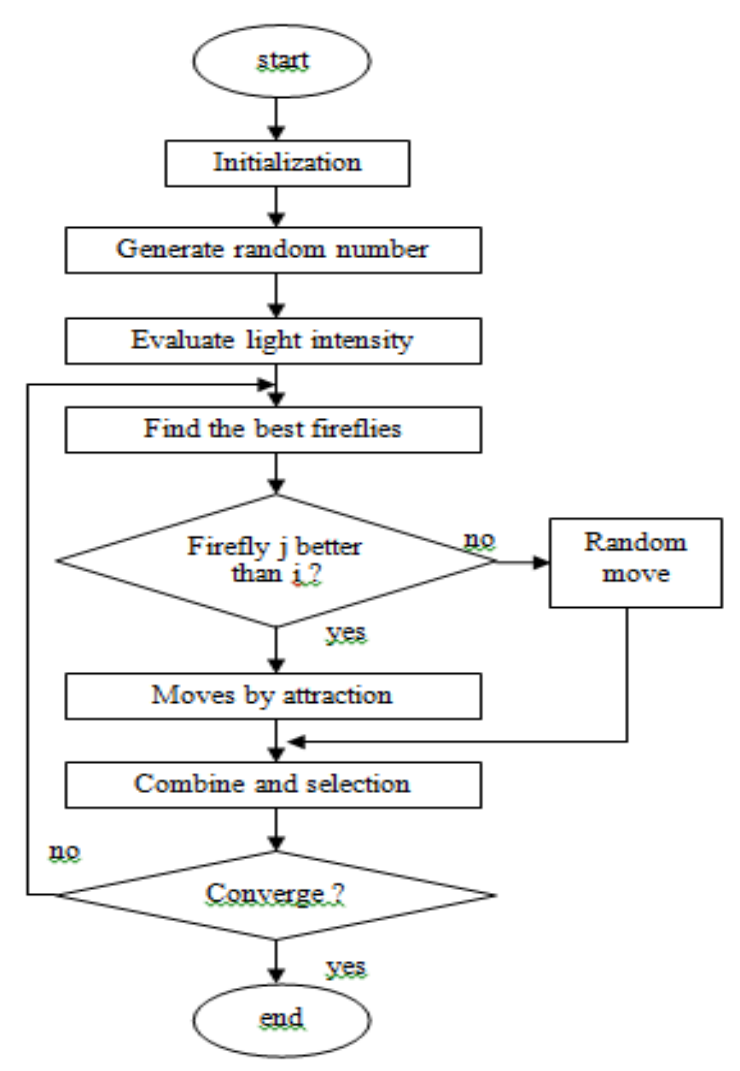

Figure 2. Flowchart of FA

Where,

$F V S I_{\text {max }}$ : fast voltage stability index

$V_{\text {min }} \quad$ : Minimum voltage magnitude in per-unit

$P_{\text {loss }} \quad$ : Real power losses

$Q_{\text {loss }} \quad$ : Reactive power losses

$Q_{D G} \quad$ : DG's injected reactive power

$\Sigma P_{G} \quad$ : Total real power generation in the system

$\Sigma P_{D} \quad$ : Total real power consumption

$\Sigma Q_{G} \quad$ : Total reactive power injection in the system

$\Sigma Q_{D} \quad$ : Total reactive power consumption

$S_{i} \quad: i$-th individual in Firefly Algorithm

Constraint (6) is significant for overall system stability assessment, while constraint (7) ensures that the voltage does not violate the system requirement. In this study, the lower limit for the voltage is set to be 0.85 per-unit rather than 0.95 per-unit due to the increasing reactive loading that will be used in the experiment. Constraint (9) and (10) is to guarantee the power balance between the point of injection and extraction (i.e. generation and consumption) for both real and reactive power.

\subsection{Loss Sensitivity}

Prior to sizing the DG's injected reactive power, the Loss Sensitivity (LS) technique will be applied for location identification in DG placement problem. The method is based on the change in losses with respect to generation increment [26], or in this case, the DG's injected power. The terms (12) and (13) represent the loss sensitivity at $k$-th bus in terms of real and reactive power respectively.

$$
\begin{aligned}
& L S_{k}=\frac{P_{\text {loss }}^{a}-P_{\text {loss }}^{b}}{\Delta P_{k}} \\
& L S_{k}=\frac{Q_{\text {loss }}^{a}-Q_{\text {loss }}^{b}}{\Delta Q_{k}}
\end{aligned}
$$


Where,
$L S_{k}$
$P_{\text {loss }}^{b}, Q_{\text {loss }}^{b}$
: Loss sensitivity at $k$-th bus in a power system
$P_{\text {loss }}^{a}, Q_{\text {loss }}^{a}$
: Real and reactive power losses before generation increment
$\Delta P_{k}, \Delta Q_{k}$
: Real and reactive power losses after generation increment
: Generation increment or DG's injected power

To obtain the losses before and after increment, at first, a load flow simulation is run for the first time to obtain the base case losses. Then, the generation increment is set at $k$-th selected bus and followed by another load flow simulation to obtain the new losses. The process is repeated until all buses has been tested and a rank of buses with corresponding LS indices is tabulated.

\section{RESULTS AND DISCUSSION}

Determining the suitable locations in IEEE 30-bus test system for DG placement was based on the Loss Sensitivity (LS) technique. In order to calculate the LS indices at all buses, the DG's injected reactive power is set to a fixed value, in this paper, $10 \mathrm{MVar}$. Based from the analysis, there are three buses with significant LS indices, which are bus 30, 29 and 27 in descending order. Table 1 tabulates the results. Based on Table 1, there are two DG installations to be considered: double and triple installation. As has been found in Table 1, double installation involves placement of DG at bus 29 and 30, while triple installation will be at those two buses plus bus 27. The performance is measured in terms of minimum voltage magnitude, real power losses and overall system stability with respect to reactive loadings. The overall system stability is measured via Fast Voltage Stability Index (FVSI) [27] as the indicator.

Table 2 tabulates the results when the reactive loadings were imposed on bus 30 . All the improvement on voltage, losses and stability with respect to reactive loadings are illustrated in Figure 3 to Figure 5. The verification on the effectiveness of the proposed FA-based DG placement was conducted with bus 30 as the test bus for reactive loading.

Table 1. LS Indices for Top 10 Buses in IEEE 30-Bus Test System - Injected $Q_{D G}=10 \mathrm{MVar}$

\begin{tabular}{ccc}
\hline Rank & Bus & LS indices \\
\hline 1 & 30 & 0.21674 \\
2 & 29 & 0.14861 \\
3 & 27 & 0.09791 \\
4 & 25 & 0.07990 \\
5 & 26 & 0.06113 \\
6 & 24 & 0.04886 \\
7 & 23 & 0.02961 \\
8 & 22 & 0.02593 \\
9 & 21 & 0.02545 \\
10 & 28 & 0.02240 \\
\hline
\end{tabular}

Table 2. Effects of DG Installation on Voltage, Losses and Stability - Reactive Loading at bus 30

\begin{tabular}{clcccccc}
\hline$Q_{D 30}$ & Condition & $\begin{array}{c}Q_{D G 1} \\
(\mathrm{MVar})\end{array}$ & $\begin{array}{c}Q_{D G 2} \\
(\mathrm{MVar})\end{array}$ & $\begin{array}{c}Q_{D G 3} \\
(\mathrm{MVar})\end{array}$ & $\begin{array}{c}V_{\min } \\
(\mathrm{p} . \mathrm{u} .)\end{array}$ & $\begin{array}{c}P_{\text {Loss }} \\
(\mathrm{MW})\end{array}$ & $\begin{array}{c}F V S I_{\max } \\
(\mathrm{p} . \mathrm{u} .)\end{array}$ \\
\hline \multirow{2}{*}{20} & Without DG & - & - & - & 0.7424 & 20.7998 & 0.4918 \\
& Triple DG & 11.6290 & 2.6661 & 41.3647 & 0.9908 & 18.2178 & 0.2555 \\
& Double DG & 18.7585 & 20.1940 & - & 0.9838 & 18.3193 & 0.2652 \\
& Without DG & - & - & - & 0.7322 & 21.0002 & 0.7881 \\
30 & Triple DG & 14.8401 & 12.4919 & 12.0949 & 0.9402 & 18.2450 & 0.2184 \\
& Double DG & 41.0217 & 16.7647 & - & 0.9878 & 18.7495 & 0.3038 \\
& Without DG & - & - & - & 0.7231 & 22.2221 & 0.7995 \\
40 & Triple DG & 18.8929 & 33.9285 & 10.2528 & 0.9858 & 19.1583 & 0.3419 \\
& Double DG & 41.0217 & 16.7647 & - & 0.9878 & 18.7495 & 0.3038 \\
& Without DG & - & - & - & 0.7100 & 23.2322 & 0.8332 \\
& Triple DG & 47.6285 & 2.0685 & 13.4324 & 0.9681 & 17.8224 & 0.1940 \\
& Double DG & 75.7127 & 1.8545 & - & 0.9875 & 19.0330 & 0.4308 \\
\hline
\end{tabular}

Improvement on the minimum voltage magnitude seems to be consistent as shown in Figure 3. This is true for double DG installation where the voltage has been improved to a satisfactory level at all loadings. For instance, the minimum voltage has been improved from 0.7424 per-unit to 0.9838 per-unit at 20 MVar loading, 0.7322 per-unit to 0.9878 per-unit at 30 MVar loading, 0.7231 per-unit to 0.9878 per-unit at 
$40 \mathrm{MVar}$ loading, and 0.7100 per-unit to 0.9875 per-unit at $50 \mathrm{MV}$ ar loading. As has been expected, the real power loss is also been minimized through double DG installation as shown in Figure 4. At every reactive loading, it manages to keep the real power losses below the pre-optimization values, i.e. the values when there is no DG installed into the system. This is proven as follows: the double DG installation results in 12 percent losses reduction at $20 \mathrm{MV}$ ar loading (i.e from 20.7998 MW to $18.3193 \mathrm{MW}$ ), 11 percent losses reduction at $30 \mathrm{MV}$ ar loading (i.e from 21.0002 $\mathrm{MW}$ to $18.7495 \mathrm{MW}$ ), 16 percent losses reduction at 40 MVar loading (i.e from 22.2221 MW to $18.7495 \mathrm{MW}$ ), and 18 percent losses reduction at 50 MVar loading (i.e from 23.2322 MW to 19.0330 MW).

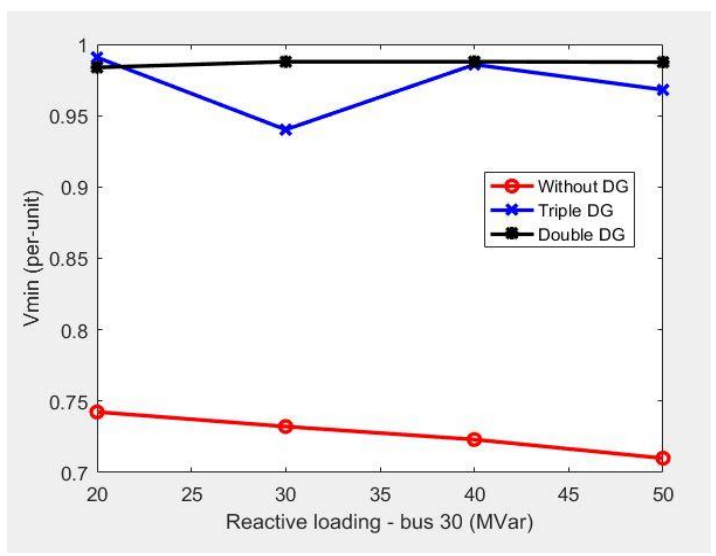

Figure 3. Effect of DG installation on voltage reactive loading bus 30

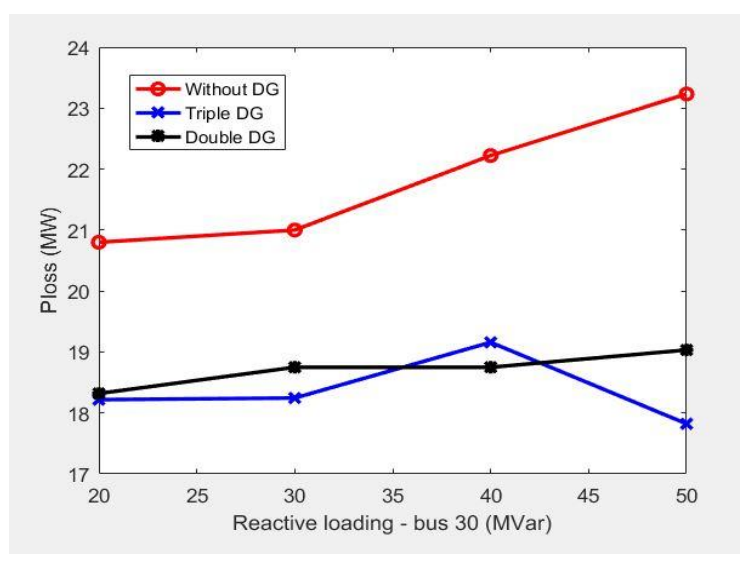

Figure 4. Effect of DG installation on losses reactive loading bus 30

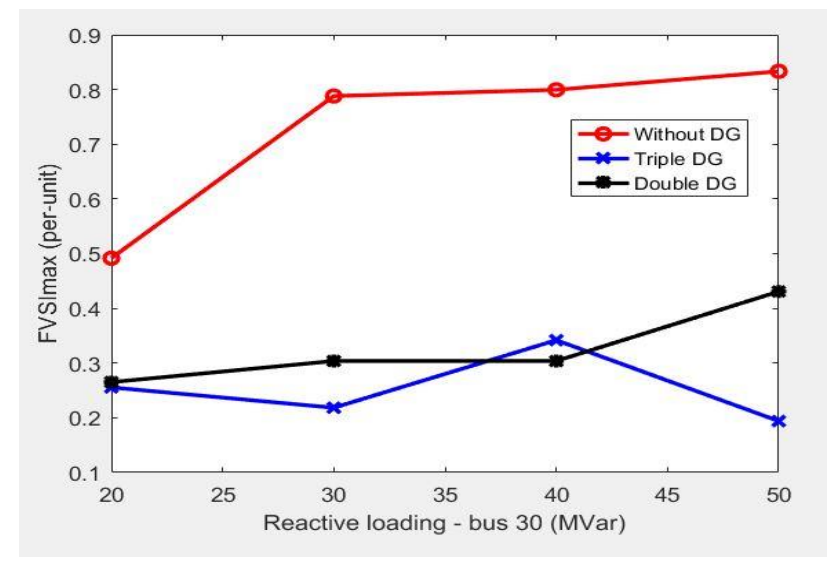

Figure 5. Effect of DG installation on stability-reactive loading bus 30

Still, the reduction percentage signifies a good performance from the DG placement. The overall system stability, as shown in Figure 5, has been successfully enhanced through the reduction of FVSI index. The triple DG installation manages to keep the value below 0.4 per-unit regardless of the loading. For example, the $F V S I_{\max }$ has been reduced from 0.4918 per-unit to 0.2555 per-unit at 20 MVar loading, 0.7881 per-unit to 0.2184 per-unit at 30 MVar loading, 0.7995 per-unit to 0.3419 per-unit at 40 MVar loading, and 0.8332 per-unit to 0.1940 per-unit at 50 MVar loading. From this analysis, it is not a mistake to say that the proposed DG placement using Firefly Algorithm (FA) is a good approach for any system operator (SO) of utilities to enhance distribution network performance, either in terms of stability, reliability and energy saving. This analysis justifies two findings: (1) the DG locations (i.e. bus 27, 29 and 30) are the most suitable locations for placement and (2) the DG's MVar capacity (i.e. $Q_{D G}$ ) as optimized by Firefly Algorithm (FA) is optimal. 


\section{CONCLUSION}

In conclusion, this paper has presented a method for optimal sizing of distributed generation (DG) using Firefly Algorithm (FA) and Loss Sensitivity (LS) technique for voltage stability enhancement. The optimization technique used in finding the optimal DG size is FA, while the LS technique was used as the indicator for the most suitable locations of DG placement. In the test system, two types of placement have been conducted namely double and triple DG installation. This study has revealed that FA-based DG placement, either double or triple installation, promises satisfactory results as the voltage magnitude, real power losses and system stability have been successfully improved. Hence, it can be said that the proposed method has solved the optimal DG allocation problem in distribution network. Therefore, it is aspired that the proposed FA-based DG placement will be extended to take into consideration some aspects ignored in this study, such as renewable energy sources (RES), investment cost, societal and environmental impact.

\section{ACKNOWLEDGEMENTS}

The authors would like to acknowledge the Institute of Research Management and Innovation (IRMI) UiTM Shah Alam, Selangor, Malaysia for the financial support of this research. This research is supported by IRMI under the Research Entity Initiative (REI) Grant Scheme with project code: 600IRMI/REI 5/3 (011/2018).

\section{REFERENCES}

[1] S. Ghosh, S. P. Ghoshal, and S. Ghosh, "Optimal sizing and placement of distributed generation in a network system," Int. J. Electr. Power Energy Syst., vol. 32, no. 8, pp. 849-856, 2010.

[2] P. S. Georgilakis, S. Member, and N. D. Hatziargyriou, "Optimal Distributed Generation Placement in Power Distribution Networks: Models, Methods, and Future Research," IEEE Trans. Power Syst., vol. 28, no. 3, pp. 3420-3428, 2013.

[3] A. F. Sarabia, "Impact of distributed generation on distribution system By," Aalborg Univ. denmark, vol. 8, no. June, pp. 42-50, 2011.

[4] S. Essallah, A. Bouallegue, and A. Khedher, "A comparative performances study of different indices for optimal DG placement in distribution system," Int. Conf. Green Energy Convers. Syst. GECS, 2017.

[5] T. Ackermann, G. Ran Andersson, and L. Sö Der, "Distributed generation: a definition," Electr. Power Syst. Res., vol. 57, pp. 195-204, 2001.

[6] M. Esmaili, "Placement of minimum distributed generation units observing power losses and voltage stability with network constraints," IET Gener. Transm. Distrib., vol. 7, no. 8, pp. 813-821, 2013.

[7] R. S. Al Abri, E. F. El-Saadany, and Y. M. Atwa, "Optimal placement and sizing method to improve the voltage stability margin in a distribution system using distributed generation," Power Syst. IEEE Trans., vol. 28, no. 1, pp. 326-334, 2013.

[8] A. Parizad, A. Khazali, and M. Kalantar, "Optimal placement of distributed generation with sensitivity factors considering voltage stability and losses indices," Proc. - 2010 18th Iran. Conf. Electr. Eng. ICEE 2010, pp. 848-855, 2010.

[9] H. Hedayati, S. A. Nabaviniaki, and A. Akbarimajd, "A new method for placement of DG units in distribution networks,” 2006 IEEE PES Power Syst. Conf. Expo. PSCE 2006 - Proc., no. August, pp. 1904-1909, 2006.

[10] V. V. S. N. Murty and A. Kumar, "Optimal placement of DG in radial distribution systems based on new voltage stability index under load growth,” Int. J. Electr. Power Energy Syst., vol. 69, pp. 246-256, 2015.

[11] S. Montoya-Bueno, J. I. Munoz, and J. Contreras, "Optimal expansion model of renewable distributed generation in distribution systems," 2014 Power Syst. Comput. Conf., p. 7, 2014.

[12] R. Oftadeh, M. J. Mahjoob, and M. Shariatpanahi, "A novel meta-heuristic optimization algorithm inspired by group hunting of animals: Hunting search," Comput. Math. with Appl., vol. 60, no. 7, pp. 2087-2098, 2010.

[13] R. C. Eberhart and Y. Shi, "Comparison between genetic algorithms and particle swarm optimization," Evol. Program. VII, pp. 611-616, 1998.

[14] G. Lindfield and J. Penny, "The Firefly Algorithm," Introd. to Nature-Inspired Optim., no. 2009, pp. 85-100, 2017.

[15] X. Xia et al., "A hybrid optimizer based on firefly algorithm and particle swarm optimization algorithm," J. Comput. Sci., 2017.

[16] P. Balachennaiah, M. Suryakalavathi, and P. Nagendra, "Firefly algorithm based solution to minimize the real power loss in a power system," Ain Shams Eng. J., vol. 9, no. 1, pp. 89-100, 2015.

[17] P. Kora and K. S. Rama Krishna, "Hybrid firefly and Particle Swarm Optimization algorithm for the detection of Bundle Branch Block," Int. J. Cardiovasc. Acad., vol. 2, no. 1, pp. 44-48, 2016.

[18] I. Fister, X. S. Yang, and J. Brest, "A comprehensive review of firefly algorithms," Swarm Evol. Comput., vol. 13, pp. 34-46, 2013.

[19] O. Olatunde, H. A Rahman, "Allocation of distributed generation and capacitor banks in distribution system," Indonesian Journal of Electrical Engineering and Computer Science, vol. 13, no. 2, pp. 437-446, February 2019. 
[20] A.Y. Abdelaziz, S. F. Mekhamer, R. H. Shehata, "Solution of distributed generation allocation problem using a novel method," Indonesian Journal of Electrical Engineering and Computer Science, vol. 15, no. 2, pp. 554-564, 2019.

[21] M. N. Bin Kamarudin, T. J. T. Hashim, and A. Musa, "Optimal sizing and location of distributed generation for loss minimization using firefly algorithm," Indonesian Journal of Electrical Engineering and Computer Science, vol. 14, no. 1, pp. 421-427, April 2019.

[22] H. Shayeghi, M. Alilou, B. Tousi, "Sizing and Placement of DG and UPQC for Improving the Profitability of Distribution System Using Multi-objective WOA," Advances in Intelligent Systems and Computing, vol. 941, pp. 810-820, 2020.

[23] T. S. Tawfeek, A. H. Ahmed, S. Hasan, "Analytical and particle swarm optimization algorithms for optimal allocation of four different distributed generation types in radial distribution networks," Energy Procedia, vol. 153, pp. 86-94, October 2018.

[24] Thuan Thanh Nguyen, Anh Viet Truong, and Tuan Anh Phung, "A novel method based on adaptive cuckoo search for optimal network reconfiguration and distributed generation allocation in distribution network," International Journal of Electrical Power \& Energy Systems, vol. 78, pp. 801-815, June 2016.

[25] Carmen L.T. Borges and Djalma, M. Falcão, "Optimal distributed generation allocation for reliability, losses, and voltage improvement," International Journal of Electrical Power \& Energy Systems, vol. 28, no. 6, pp. 413-420, July 2006.

[26] J. Zhu, Optimization of Power System Operation. John Wiley and Sons, 2009.

[27] I. Musirin and T. K. A. Rahman, "Novel fast voltage stability index (FVSI) for voltage stability analysis in power transmission system," Student Conference on Research and Development, Shah Alam, Malaysia, July 2002 